\title{
Modification of Gold Surface with Gold Nanoparticles and Cyclohexyl Dithiocarbamate as a Selective Sensor for Cysteine
}

\author{
Ehab AlShamaileh, ${ }^{1,2}$ Haytham Saadeh, ${ }^{1}$ and Valerie Favry ${ }^{2}$ \\ ${ }^{1}$ Department of Chemistry, Faculty of Science, The University of Jordan, Amman 11942, Jordan \\ ${ }^{2}$ Faculty of Sciences and Humanities, Salman bin Abdulaziz University, Al-Kharj 11942, Saudi Arabia \\ Correspondence should be addressed to Ehab AlShamaileh; ehab@ju.edu.jo
}

Received 21 November 2012; Accepted 5 December 2012

Academic Editor: Concha Gimeno

Copyright (C) 2013 Ehab AlShamaileh et al. This is an open access article distributed under the Creative Commons Attribution License, which permits unrestricted use, distribution, and reproduction in any medium, provided the original work is properly cited.

The self-assembly of cyclohexylamine dithiocarbamate $\left(\mathrm{C}_{6} \mathrm{DTC}\right)$ on gold $(\mathrm{Au})$ and gold nanoparticles (AuNPs) was studied electrochemically using cyclic voltammetry $(\mathrm{CV})$. Cyclic voltammetry was used to study the system $\mathrm{Fe}(\mathrm{CN})_{6}{ }^{3-} / \mathrm{Fe}(\mathrm{CN})_{6}{ }^{4-}$ at the electrode surface of $\left(\mathrm{C}_{6} \mathrm{DTC} / \mathrm{Au}\right)$ and $\left(\mathrm{C}_{6} \mathrm{DTC} / \mathrm{AuNPs}\right)$. The application of the resulting chemically modified surface as a selective sensor for cysteine, among other amino acids, was investigated. Linear oxidative desorption technique was used to characterize the modified electrode that consists of the self-assembled monolayer of cyclohexylamine dithiocarbamate on gold nanoparticles deposited on $\mathrm{Au}$ electrode $\left(\mathrm{C}_{6} \mathrm{DTC} / \mathrm{AuNPs} / \mathrm{Au}\right)$. The results showed an enhancement in the oxidation peak of cysteine on the modified electrode and hence a greater sensitivity.

\section{Introduction}

Dithiocarbamate derivatives have been extensively studied due to their antimicrobial activity [1] and the various applications in industrial and chemical processes, such as vulcanization accelerators [2], flotation agents, fungicides [3], pesticides [4], and corrosion inhibitors [5]. One of the most interesting properties of dithiocarbamates is their strong metal-binding ability and the ease to form self-assembled monolayers (SAMs) on gold surfaces making them useful to many applications. The structural features of SAMs on gold surfaces are dictated by two major factors: the sulfur gold interaction and the organic interchain interaction. It has been shown that both sulfur atoms in the headgroup of a dithiocarbamate chemically bond to the surface of gold [6].

Owing to their large surface area and biocompatibility, many nanostructured materials represent a powerful detection platform for a broad range of sensors including biological, electrochemical, gas, optical, $\mathrm{pH}$, and molecular orientation. The sensing devices may include individual nanostructured sensors, multi-nanostructured sensors, nanostructured film sensors, and others. These nanosensors have a number of key features, including high sensitivity, exquisite selectivity, fast response and recovery, and potential for integration of addressable arrays on a massive scale, which set them apart from other sensors technologies $[7,8]$. Many researchers agree that more development is needed at the molecular level of detection to improve miniature and nanosensor devices.

Cysteine (2-amino-3-mercaptopropoinic acid) is a biologically important substance in living systems and its oxidized form (cysteine) is utilized as a model of the thiol group in proteins. Cysteine, mainly the L-enantiomer, is a precursor in the food, pharmaceutical, and personal care industries. One of the largest applications is the production of flavors. For example, L-cysteine is used as a processing aid for baking while the reaction of cysteine with sugars yields meat flavors [9].

Very little research targeted the selective sensing of cysteine due to difficulties arising from the structural similarity with $\alpha$-amino acids and peptides (carboxylic and amino groups). The need to improve the sensing selectivity of cysteine is therefore obvious. Dithiocarbamates attached to gold nanoparticles have already been tested in the electrochemical sensing for dopamine and ascorbic acid [10]. 


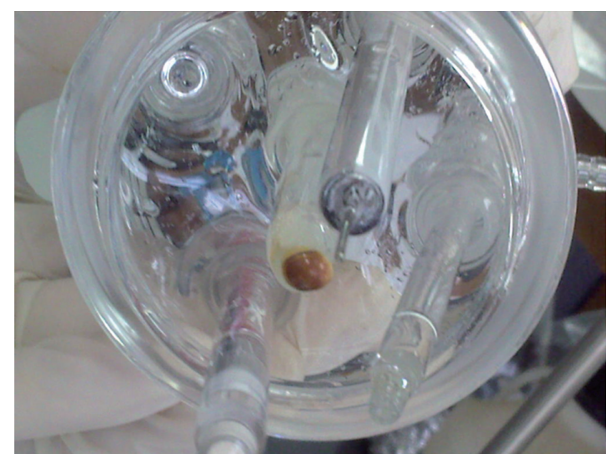

FIGURE 1: A photograph showing the three-electrode setup where the visible light red color electrode is the surface of the nanogold electrode (AuNPs/Au).

In this paper, cyclohexylamine dithiocarbamate is selfassembled onto gold $\mathrm{(Au}$ ) and nanogold (gold electrode with adsorbed gold nanoparticles; AuNPs/Au) and the chemically modified electrode was tested as a sensor for several aminoacids including cysteine.

\section{Experimental}

2.1. Chemicals. Cyclohexylamine was purchased from Aldrich (99\%), sodium hydroxide $\mathrm{NaOH}$ (Aldrich), carbon disulfide $\mathrm{CS}_{2}$ (97\%) and ethanol, absolute (99\%), sulfuric acid $\mathrm{H}_{2} \mathrm{SO}_{4}(98 \%)$, potassium ferrocyanide $\left(\mathrm{K}_{3} \mathrm{Fe}(\mathrm{CN})_{6}\right)$ (99.0\%), potassium chloride (99.9\%), $\mathrm{HAuCl}_{4}(99.9 \%)$ and ammonium peroxydisulfate $\left(\mathrm{NH}_{4}\right)_{2} \mathrm{~S}_{2} \mathrm{O}_{8}(99 \%)$ were all of analytical grade and used as received. All solutions were prepared with triply distilled water.

2.2. Instrumentation. Cyclic voltammetry experiments were carried out with a VoltaLab PGZ 100 potentiostat in a double-wall three-electrode glass cell under nitrogen (Figure 1). Solutions were degassed with ultrapure nitrogen for about 20 minutes before electrochemical measurements. The working electrode (WE) was a gold polycrystalline electrode embedded in a glass tube with a surface diameter of $3.0 \mathrm{~mm}$. Prior to measurements, the surface of the working electrode was carefully polished with alumina slurry, rinsed several times, and then sonicated for about 1 minute. Afterwards, the electrode was electrochemically cleaned in $0.5 \mathrm{M} \mathrm{H}_{2} \mathrm{SO}_{4}$ until a stable and acceptable gold oxidation/reduction $\mathrm{CV}$ was obtained.

All reported potential values are versus the SCE reference electrode and all measurements were carried out at around $20^{\circ} \mathrm{C}$. A platinum wire was used as the auxiliary electrode. Solutions' $\mathrm{pH}$ values were measured with a Hanna calibrated digital pH meter (Switzerland).

All glassware for electrochemical experiments were carefully cleaned by immersion in a solution of concentrated sulfuric acid containing ammonium peroxydisulfate $\left(\mathrm{NH}_{4}\right)_{2} \mathrm{~S}_{2} \mathrm{O}_{8}$ for 10 hours followed by copious rinsing with deionised and triply-distilled water.
2.3. Synthesis of Cyclohexyl Dithiocarbamate $\left(C_{6} D T C\right)$. The sodium salt of cyclohexyl dithiocarbamate $\left(\mathrm{C}_{6} \mathrm{DTC}\right)$ was synthesized as reported in the literature with modification [11]. To summarize, the $\mathrm{C}_{6}$ DTC was prepared by reacting cyclohexylamine with an equimolar ratio of $\mathrm{CS}_{2}$ and $\mathrm{NaOH}$ solutions in an ice bath. To $0.1 \mathrm{M}$ of $\mathrm{NaOH}$, dissolved in minimum water, cyclohexylamine in $50 \mathrm{~mL}$ of ethanol $(0.1 \mathrm{M})$ was added. After thorough stirring, an ethanolic solution of $0.1 \mathrm{M} \mathrm{CS}_{2}$ was added drop wise. The reaction was stirred for 1 hour at $0-5^{\circ} \mathrm{C}$ followed by another hour at ambient temperature $\left(\sim 22^{\circ} \mathrm{C}\right)$. The solid product was filtered and washed with cold water/ethanol solution giving a white product which is then recrystallised from ethanol (yield = $60 \%$, m.p 130 $\left.{ }^{\circ} \mathrm{C}\right)$. IR/ $/ \mathrm{cm}^{-1}: 3350(-\mathrm{OH}), 3200(-\mathrm{NH}), 1480$ $(\mathrm{C}-\mathrm{N})$, and $990(\mathrm{C}=\mathrm{S})$.

2.4. Preparation of the Nanogold Electrode (AuNPs/Au). The $\mathrm{Au}$ electrode surface was freshly polished prior to use with $0.05 \mu \mathrm{m} \alpha-\mathrm{Al}_{2} \mathrm{O}_{3}$ slurry, and rigorously rinsed with doubly distilled water. The electrode was successively ultrasonically rinsed with $98 \% \mathrm{H}_{2} \mathrm{SO}_{4}$ and $95 \%$ ethanol and distilled water for 10 minutes, dried with nitrogen gas, and then electrochemically cycled in $1.0 \mathrm{M} \mathrm{H}_{2} \mathrm{SO}_{4}$ until a stable gold oxide formation/reduction $\mathrm{CV}$ was obtained (Figure 2(a)). The electrode was then immersed into $3 \mathrm{mM} \mathrm{HAuCl}_{4}$ solution containing $1.0 \mathrm{M} \mathrm{H}_{2} \mathrm{SO}_{4}$ solution as an electrolyte, and electrochemical deposition of gold nanoparticles was conducted by the electrochemical scanning the electrode between a potential of $-200 \mathrm{mV}$ and $-190 \mathrm{mV}$ (versus SCE) for a selected number of times at a scan rate of $10 \mathrm{mV} / \mathrm{s}$. The electrode surface showed a very visible light red color indicating the presence of gold nanoparticles as shown in the photograph in Figure 1. We call the resulting surface the nanogold electrode (AuNPs/Au). After experiments, the electrode was regenerated by soaking it in piranha solution (a mixture of $3: 7, \mathrm{v} / \mathrm{v}$ of $30 \% \mathrm{H}_{2} \mathrm{O}_{2}$ and $98 \% \mathrm{H}_{2} \mathrm{SO}_{4}$ ) overnight and then rinsing it with $95 \%$ ethanol and distilled water followed by drying in a stream of nitrogen gas.

\subsection{Preparation of $C_{6} D T C-S A M s$ on the Gold Electrode} $\left(C_{6} D T C / A u\right)$. The electrode was initially cleaned in the same way described in 2.4 above. The $\mathrm{C}_{6} \mathrm{DTC} / \mathrm{Au}$ were prepared by immersing the gold electrode in freshly prepared aqueous solutions of $1.0 \mathrm{mM}$ of cyclohexyl dithiocarbamate $\left(\mathrm{C}_{6} \mathrm{DTC}\right)$ solution at ambient temperature for 6 hours followed by another 6 hours in triply distilled water to remove any physically adsorbed molecules. The electrode was then rinsed with water and dried in a stream of nitrogen gas.

2.6. Preparation of the $C_{6} D T C-M o d i f i e d ~ N a n o g o l d ~ E l e c-$ trode $\left(C_{6} D T C / A u N P s / A u\right)$. The electrode was cleaned and nanogold was deposited as described in 2.4 above. The selfassembly of $\mathrm{C}_{6}$ DTC was accomplished with the immersion of the electrode into a freshly prepared $1 \mathrm{mM} \mathrm{C}_{6} \mathrm{DTC}$ aqueous solution for $24 \mathrm{~h}$ in the dark at room temperature. The modified electrode was then taken out, soaked in triply distilled water for $6 \mathrm{~h}$, and finally dried in a stream of nitrogen gas. 


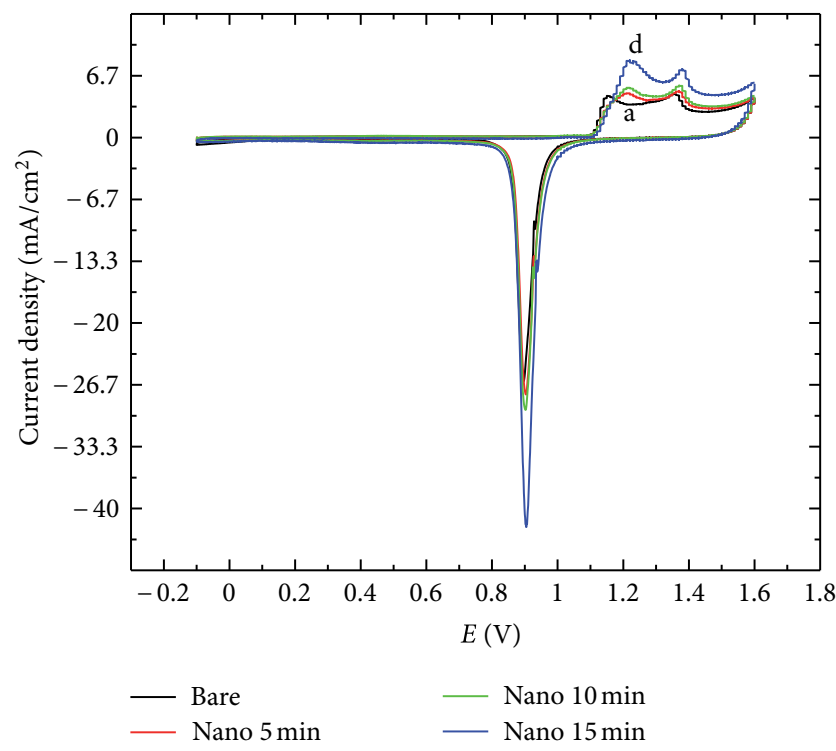

FIGURE 2: Cyclic voltammograms of (a) bare gold electrode, (b) nanogold electrode with deposition time of $5 \mathrm{~min}$, (c) nanogold electrode with deposition time of $10 \mathrm{~min}$, and (d) nanogold electrode with deposition time of $15 \mathrm{~min}$. Electrolyte: aqueous $1.0 \mathrm{M} \mathrm{H}_{2} \mathrm{SO}_{4}$ solution. Scan rate $=50 \mathrm{mV} / \mathrm{s}$.

\section{Results and Discussion}

This section is divided into three parts. In the first part, the $\left(\mathrm{C}_{6} \mathrm{DTC} / \mathrm{Au}\right)$ and $\left(\mathrm{C}_{6} \mathrm{DTC} / \mathrm{AuNP} / \mathrm{Au}\right)$ are investigated using cyclic voltammetry. The redox system of $\mathrm{Fe}(\mathrm{CN})_{6}{ }^{3-}$ / $\mathrm{Fe}(\mathrm{CN})_{6}{ }^{4-}$ is studied on both electrodes using cyclic voltammetry in the second part. Finally, the $\mathrm{C}_{6} \mathrm{DTC}$-modified nanogold electrode, $\mathrm{C}_{6} \mathrm{DTC} / \mathrm{AuNPs} / \mathrm{Au}$, is tested for the electrooxidation of cysteine.

3.1. Cyclic Voltammetry of the Electrode Surface of $\left(C_{6} D T C /\right.$ $A u)$ and $\left(C_{6} D T C / A u N P s / A u\right)$. Figure 2 shows cyclic voltammograms (CVs) of the bare gold electrode and nanogold electrodes in deoxygenated $1.0 \mathrm{M} \mathrm{H}_{2} \mathrm{SO}_{4}$ solution. The nanogold particles were deposited at 5,10 , and 15 minutes. We noticed that further deposition (over 15 minutes) resulted in CVs different from that for the polycrystalline gold mainly with extra and sharper peaks. We chose the 5-minute modification time in all experiments to eliminate any complications that may result from producing different surfaces at different deposition times. We also noticed that more deposition deepens the color of the electrode and makes it more difficult to regenerate to a clean gold electrode afterwards. Previous studies showed that small deposition times give reasonable and acceptable modification of the gold electrode with gold nanoparticles [12]. The relative surface area of the electrode could be estimated from the coulombic integration of the reductive waves of gold oxide [13]. By analyzing Figure 2, the ratio of the surface area of the nanogold electrode to that of the bare gold electrode is around 1.1:1 for the 5-minute deposition time and 1.8:1 for the 15-minute deposition time. Studying the electrochemical behavior of the electrode as a function of gold nanoparticles deposition time, we conclude

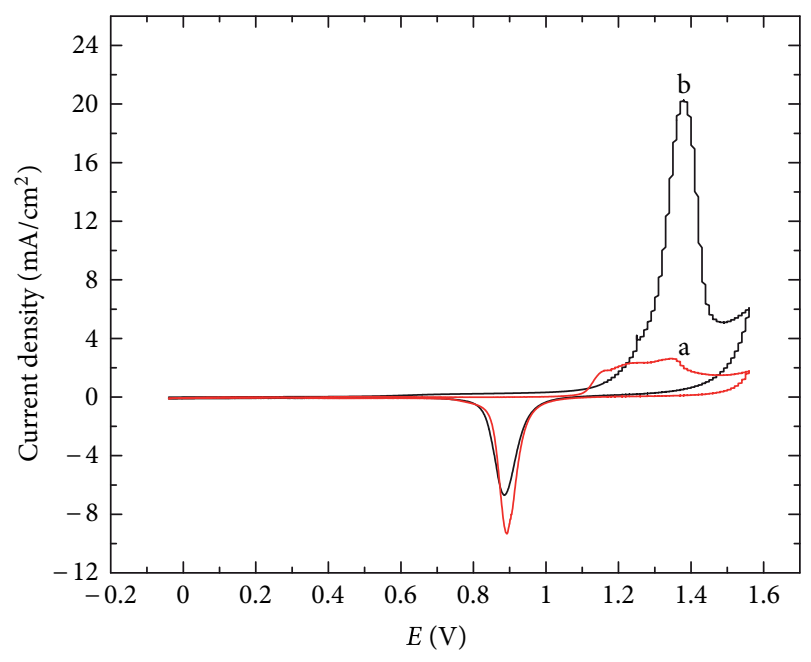

Figure 3: CV of (a) bare gold and (b) $\mathrm{C}_{6} \mathrm{DTC} / \mathrm{Au}$ electrodes in aqueous $0.5 \mathrm{M} \mathrm{H}_{2} \mathrm{SO}_{4}$ solution. Scan rate $=50 \mathrm{mV} / \mathrm{s}$.

that there is no significant change in the main reduction peak potential as a function of gold nanoparticles deposition time.

Figure 3 shows the cyclic voltammograms of bare $\mathrm{Au}$ and $\mathrm{C}_{6} \mathrm{DTC} / \mathrm{Au}$ electrodes in $0.5 \mathrm{M} \mathrm{H}_{2} \mathrm{SO}_{4}$ solution at a potential scan rate of $50 \mathrm{mV} / \mathrm{s}$. A more diluted $\mathrm{H}_{2} \mathrm{SO}_{4}$ solution was used here and onwards to increase the $\mathrm{pH}$ value and therefore avoid any interference with the organic molecule: $\mathrm{C}_{6}$ DTC. When the potential was scanned above $+800 \mathrm{mV}$, a $\mathrm{C}_{6}$ DTC desorption peak was noticed. Therefore, all following experiments involving the $\mathrm{C}_{6} \mathrm{DTC}$ molecule were limited to a maximum potential of $+600 \mathrm{mV}$. We found that when the scanning is continued to higher potentials $(>+800 \mathrm{mV})$, the peaks' intensity decreased and the CV became very similar to the bare gold electrode CV (not shown here).

Figure 4 shows the cyclic voltammograms of AuNPs and $\mathrm{C}_{6} \mathrm{DTC} / \mathrm{AuNPs}$ electrodes in $0.5 \mathrm{M} \mathrm{H}_{2} \mathrm{SO}_{4}$ at a potential scan rate of $50 \mathrm{mV} / \mathrm{s}$. The oxidation behavior is similar to that of the bare polycrystalline gold except that the $\mathrm{C}_{6} \mathrm{DTC}$ desorption peak is much broader. In a similar manner to the bare surface, all following experiments were performed at potential values under $+600 \mathrm{mV}$.

3.2. Cyclic Voltammetry of $\mathrm{Fe}(\mathrm{CN})_{6}{ }^{3-} / \mathrm{Fe}(\mathrm{CN})_{6}{ }^{4-}$ at the Electrode Surface of $\left(C_{6} D T C / A u\right)$ and $\left(C_{6} D T C / A u N P s\right)$. Figure 5 shows the cyclic voltammograms of bare $A u$ and $\mathrm{C}_{6} \mathrm{DTC} / \mathrm{Au}$ electrodes in $5 \mathrm{mM}$ potassium ferrocyanide with $0.1 \mathrm{M} \mathrm{KCl}$ as the supporting electrolyte at a potential scan rate of $50 \mathrm{mV} / \mathrm{s}$. We notice from the figure that the bare Au electrode (Figure 5(a)) shows a reversible voltammogram for the redox couple indicating that the electron transfer reaction is mainly diffusion controlled. On the other hand, the absence of major peaks in the CVs of the $\mathrm{C}_{6} \mathrm{DTC} / \mathrm{Au}$ electrode (Figure 5(b)) shows that the redox reaction has been somehow inhibited.

As illustrated in Figure 5(b), the CV exhibits perfect blocking behavior which means that a highly ordered, compact monolayer is formed on the Au surface. This is also proven by the EIS measurements where the modified 


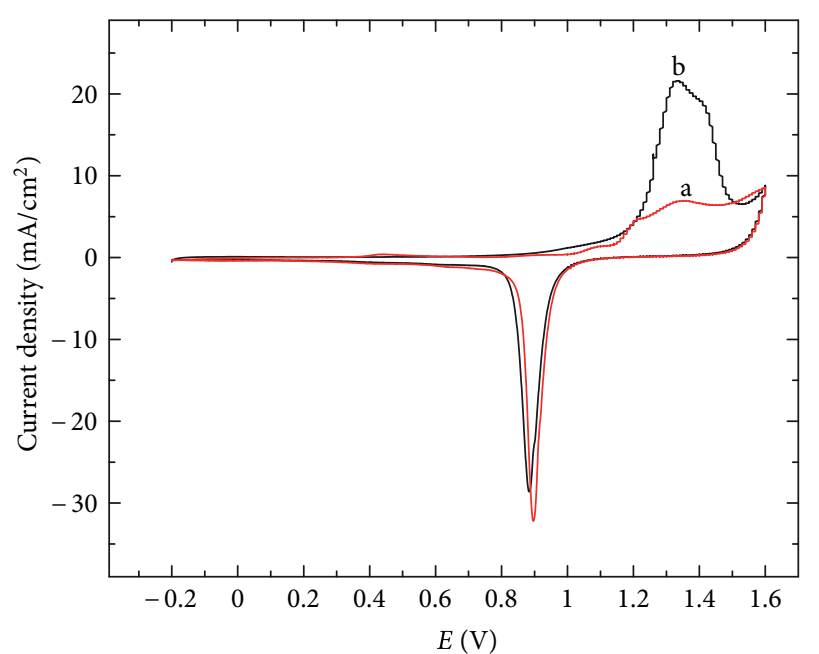

Figure 4: CV of (a) AuNPs electrode and (b) $\mathrm{C}_{6}$ DTC/AuNPs in aqueous $0.5 \mathrm{M} \mathrm{H}_{2} \mathrm{SO}_{4}$ solution. Scan rate $=50 \mathrm{mV} / \mathrm{s}$.

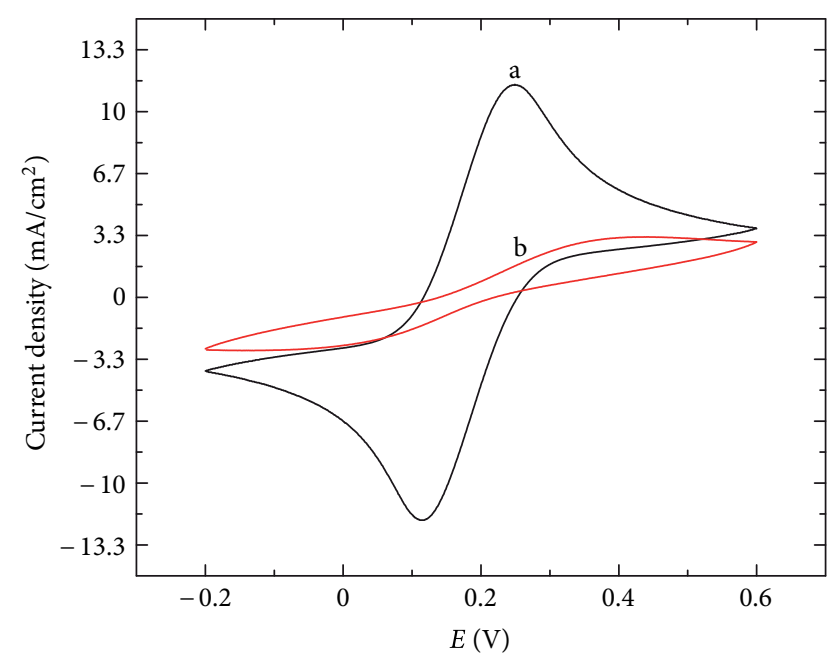

FIgUre 5: Cyclic voltammograms of (a) bare Au and (b) $\mathrm{C}_{6} \mathrm{DTC} / \mathrm{Au}$ electrodes in $5 \mathrm{mM}$ potassium ferrocyanide with $0.1 \mathrm{M} \mathrm{KCl}$ as the supporting electrolyte at a potential scan rate of $50 \mathrm{mV} / \mathrm{s}$.

interface displays a much higher resistance compared to that of the bare surface [14].

Figure 6 shows the cyclic voltammograms obtained for the nanogold modified electrode in $5 \mathrm{mM}$ potassium ferrocyanide in $0.1 \mathrm{M} \mathrm{KCl}$ as the supporting electrolyte at a potential scan rate of $50 \mathrm{mV} / \mathrm{s}$.

The bare Au electrode witnessed a pair of well-defined redox peaks with the anodic $\left(E_{\mathrm{pa}}\right)$ and cathodic $\left(E_{\mathrm{pc}}\right)$ peak potential of $0.236 \mathrm{~V}$ and $0.124 \mathrm{~V}$, respectively, and a peak potential difference of $112 \mathrm{mV}$ (curve a). These peaks are attributed to the redox behavior of the $\left[\mathrm{Fe}(\mathrm{CN})_{6}{ }^{3-/ 4-}\right]$ electrochemical system. The self-assembly of $\mathrm{C}_{6}$ DTC monolayer on electrode surface induced a small decrease of peak current, which was invoked by the diffusion inhibition of $\left[\mathrm{Fe}(\mathrm{CN})_{6}{ }^{3-/ 4-}\right]$ to the electrode surface (curve c). The modification with gold nanoparticles increased the effective electrode surface area and enhanced the rate of electron

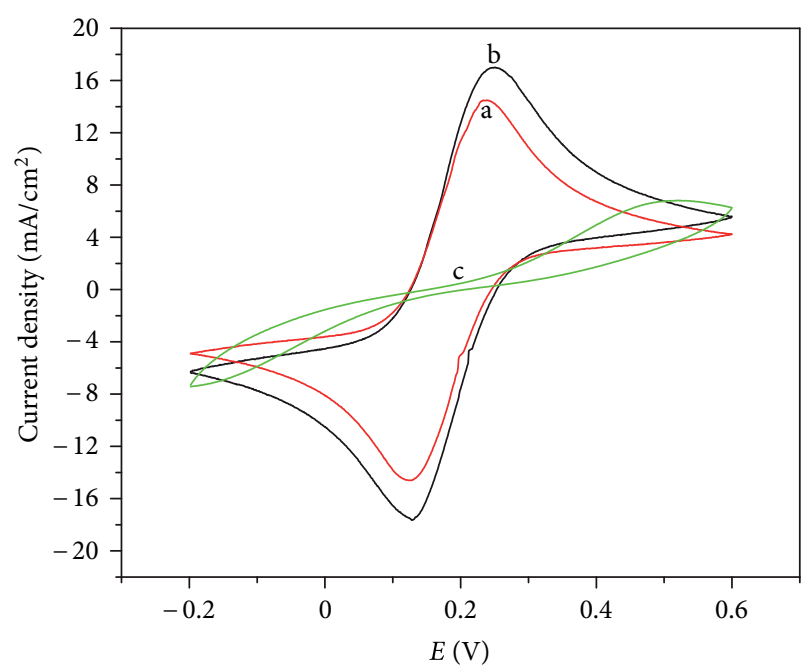

Figure 6: Cyclic voltammograms of (a) $\mathrm{C}_{6}$ DTC/AuNPs electrode (red curve), (b) nanogold AuNPs electrode (black curve) and (c) bare $\mathrm{Au}$ electrode (green curve) in $5 \mathrm{mM}$ potassium ferrocyanide with $0.1 \mathrm{M} \mathrm{KCl}$ as the supporting electrolyte at a potential scan rate of $50 \mathrm{mV} / \mathrm{s}$.

transfer, which was evidenced by a slight increase in the voltammetric responses of $\left[\mathrm{Fe}(\mathrm{CN})_{6}{ }^{3-/ 4-}\right]$ compared to that of the bare electrode (curve b).

3.3. Linear Oxidative Desorption of Cysteine on the $C_{6} D T C$ Modified Nanogold Electrode. The linear oxidative desorption of an aqueous solution of $1 \mathrm{mM}$ cysteine was performed on bare gold electrode (Figure 7(a)). No oxidation peaks were detected under a potential of $600 \mathrm{mV}$. Upon the deposition of gold nanoparticles on Au producing the AuNPs electrode, a slight increase in the measured current was seen in the region of $300 \mathrm{mV}$ and above (Figure 7(b)) compared to the bare $\mathrm{Au}$ electrode (Figure 7(a)). C $_{6}$ DTC was assembled on both bare $\mathrm{Au}$ and AuNPs electrodes. The linear oxidative desorption curve was measured. For the $\mathrm{C}_{6} \mathrm{DTC} / \mathrm{Au}$, a desorption broad peak started to appear below $200 \mathrm{mV}$ and peaked at around $500 \mathrm{mV}$ (Figure $7(\mathrm{c})$ ). Some $\mathrm{C}_{6} \mathrm{DTC}$ desorption might be attributed to this curve in addition to the oxidation of cysteine. The curve in Figure 7(d) is a linear desorption of $1 \mathrm{mM}$ cysteine on the $\mathrm{C}_{6} \mathrm{DTC}$-modified nanogold electrode $\left(\mathrm{C}_{6} \mathrm{DTC} / \mathrm{AuNPs} / \mathrm{Au}\right)$. The curve shows the presence of two major peaks in the regions -100 to $-50 \mathrm{mV}$ and 300 to $400 \mathrm{mV}$. It is clear that the modified electrode has better sensitivity compared to the other electrodes. The $400 \mathrm{mV}$ peak potential is more negative than that in the $\mathrm{C}_{6} \mathrm{DTC} / \mathrm{Au}$ electrode which indicates that nanogold plays an important role in lowering the peak potential. The two peaks in curve $\mathrm{d}$ can be employed as a basis in the fabrication of a selective sensor for cysteine in aqueous solutions due to their high current values. In addition, the combination of gold nanoparticle and $\mathrm{C}_{6} \mathrm{DTC}$ modification clearly increased the bonding of $\mathrm{C}_{6} \mathrm{DTC}$ to the gold surface and enhanced the selfassembly stability (compare curve $d$ with c). When a $\mathrm{C}_{6}$ DTCmodified nanogold electrode was stored in a buffer solution (pH 7.0) for at least 1 month at $\sim 5^{\circ} \mathrm{C}$, the electrode retained 


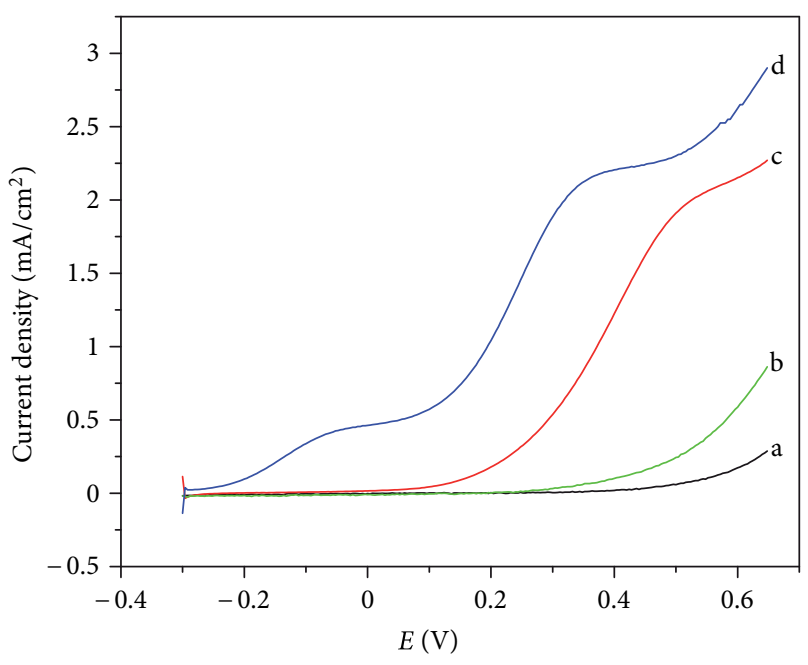

FIGURE 7: Linear oxidative desorption of $1 \mathrm{mM}$ aqueous solution of cysteine in a buffer $\mathrm{pH}=7$ on (a) bare Au, (b) AuNPs, (c) $\mathrm{C}_{6} \mathrm{DTC} / \mathrm{Au}$, and (d) $\mathrm{C}_{6} \mathrm{DTC} / \mathrm{AuNPs} / \mathrm{Au}$ electrodes. Scan rate $=50 \mathrm{mV} / \mathrm{s}$.

about $95 \%$ of its initial response provided that the potential is kept below $600 \mathrm{mV}$.

\section{Conclusions}

An electrochemical method for sensing cysteine has been tested. It consists of a self-assembled monolayer of cyclohexylamine dithiocarbamate on gold nanoparticles deposited on $\mathrm{Au}$ electrode. Cyclic voltammetry (CV) and linear oxidative desorption were used to characterize the modified electrode. We also conclude that gold nanoparticle modification increased the bonding of $\mathrm{C}_{6}$ DTC to the gold surface and enhanced its stability.

\section{Acknowledgments}

The authors thank the Faculty of Scientific Research at the University of Jordan for their financial support.

\section{References}

[1] L. Ronconi, C. MacCato, D. Barreca, R. Saini, M. Zancato, and D. Fregona, "Gold(III) dithiocarbamate derivatives of Nmethylglycine: an experimental and theoretical investigation," Polyhedron, vol. 24, no. 4, pp. 521-531, 2005.

[2] P. J. Nieuwenhuizen, A. W. Ehlers, J. G. Haasnoot, S. R. Janse, J. Reedijk, and E. J. Baerends, "The mechanism of zinc(II)-dithiocarbamate-accelerated vulcanization uncovered; theoretical and experimental evidence," Journal of the American Chemical Society, vol. 121, no. 1, pp. 163-168, 1999.

[3] K. W. Weissmahr, C. L. Houghton, and D. L. Sedlak, "Analysis of the dithiocarbamate fungicides ziram, maneb, and zineb and the flotation agent ethylxanthogenate by ion-pair reversed-phase HPLC," Analytical Chemistry, vol. 70, no. 22, pp. 4800-4804, 1998.

[4] M. A. Kamrin, Pesticide Profiles: Toxicity, Environmental Impact, and Fate, CRC Press, New York, NY, USA, 1997.
[5] A. E. Al-Rawajfeh and E. M. Al-Shamaileh, "Inhibition of corrosion in steel water pipes by ammonium pyrrolidine dithiocarbamate (APDTC)," Desalination, vol. 206, no. 1-3, pp. 169-178, 2007.

[6] R. Colorado, R. J. Villazana, and T. R. Lee, "Self-assembled monolayers on gold generated from aliphatic dithiocarboxylic acids," Langmuir, vol. 14, no. 22, pp. 6337-6340, 1998.

[7] X. J. Huang and Y. K. Choi, "Chemical sensors based on nanostructured materials," Sensors and Actuators B, vol. 122, no. 2, pp. 659-671, 2007.

[8] R. N. Goyal, A. Ali Umar, and M. Oyama, "Comparison of spherical nanogold particles and nanogold plates for the oxidation of dopamine and ascorbic acid," Journal of Electroanalytical Chemistry, vol. 631, no. 1-2, pp. 58-61, 2009.

[9] A. Asghar and A. R. Bhatti, "Advances in food research," in Advances in Food and Nutrition Research, O. . Chichester, Ed., vol. 31, p. 410, Academic Press, Boston, Mass, USA, 1986.

[10] M. Li, F. Gao, P. Yang, L. Wang, and B. Fang, "Conveniently assembling dithiocarbamate and gold nanoparticles onto the gold electrode: a new type of electrochemical sensors for biomolecule detection," Surface Science, vol. 602, no. 1, pp. 151-155, 2008.

[11] H. Gilman and A. H. Blatt, Organic Synthesis, Collective, vol. 1, John Wiley \& Sons, New York, NY, USA, 1958.

[12] E. Spain, B. Miner, T. E. Keyes, and R. J. Forster, "Regio selective functionalisation of gold nanoparticles with DNA," Chemical Communications, vol. 48, no. 6, pp. 838-840, 2012.

[13] S. F. Liu, X. H. Li, Y. C. Li, Y. F. Li, J. R. Li, and L. Jiang, "The influence of gold nanoparticle modified electrode on the structure of mercaptopropionic acid self-assembly monolayer," Electrochimica Acta, vol. 51, no. 3, pp. 427-431, 2005.

[14] E. AlShamaileh, A. Al-Rawajfeh, and V. Favry, in preparation. 

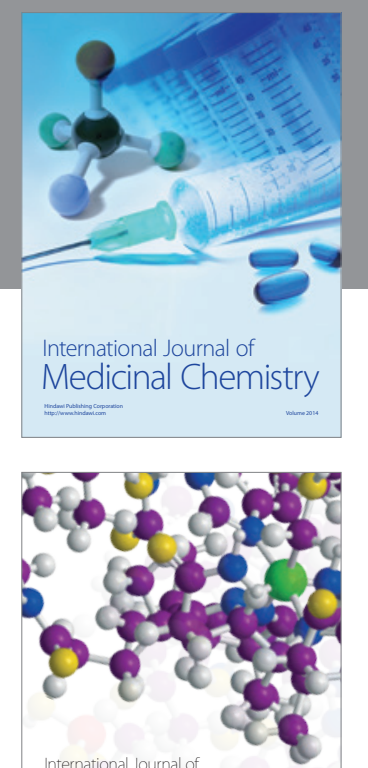

\section{Carbohydrate} Chemistry

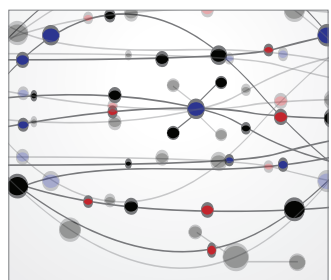

The Scientific World Journal
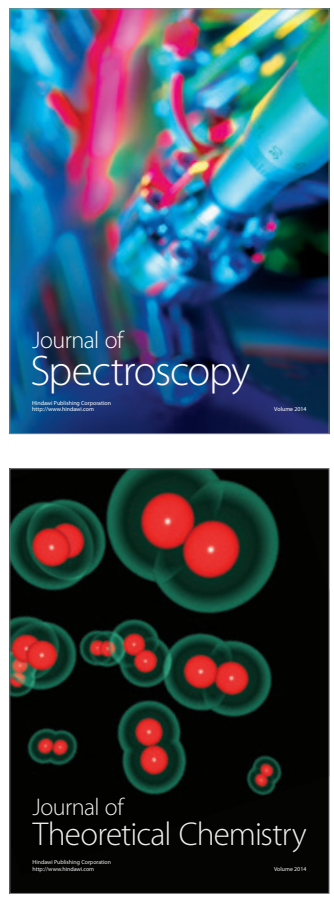
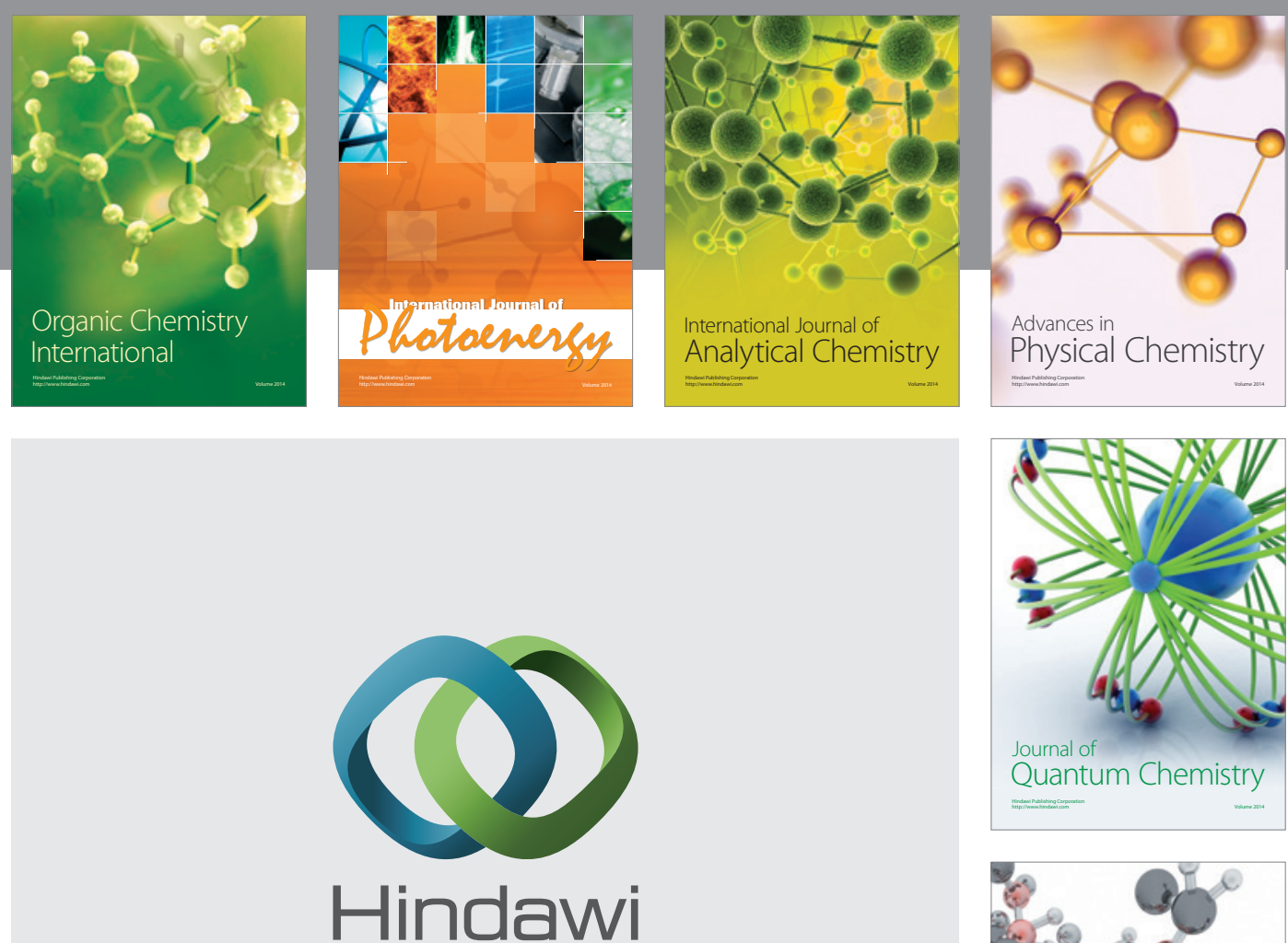

Submit your manuscripts at

http://www.hindawi.com

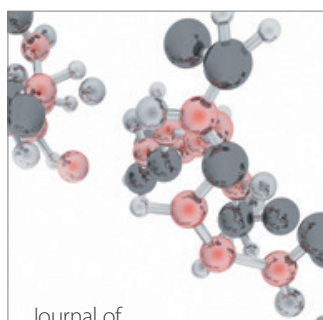

Analytical Methods

in Chemistry

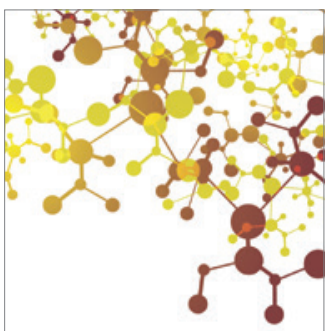

Journal of

Applied Chemistry

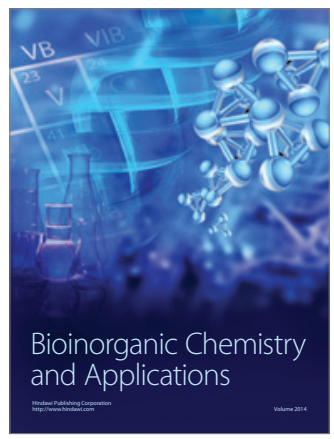

Inorganic Chemistry
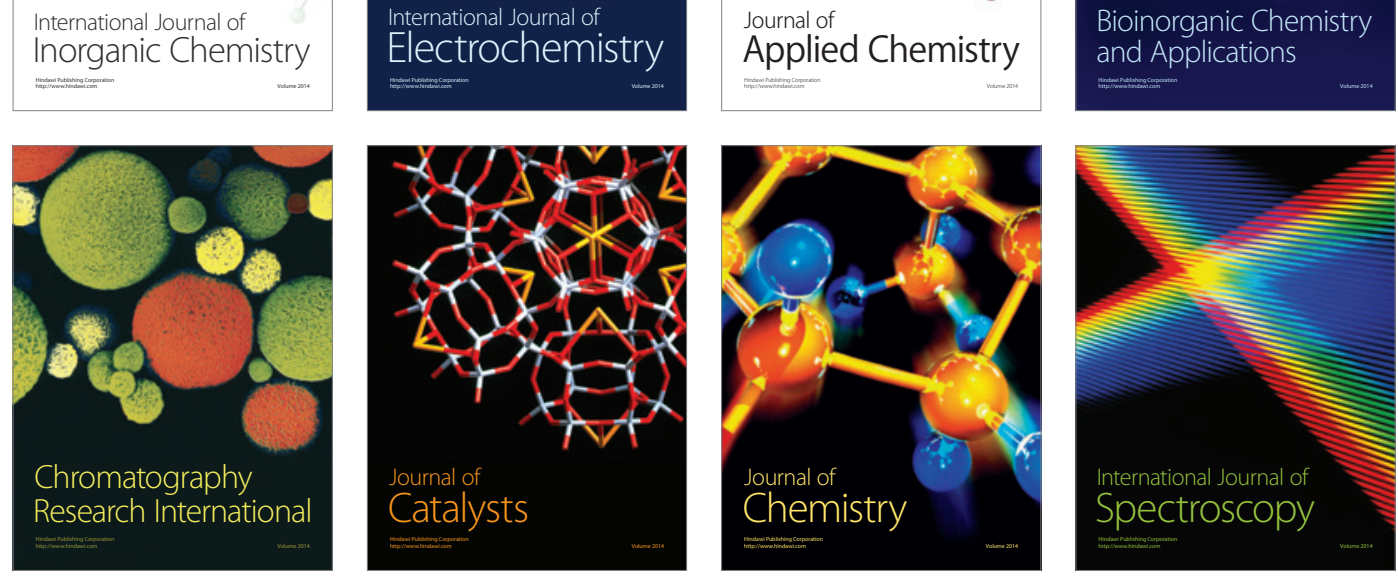